\title{
Analisis Torsional Rigidity, Efek Jacking, dan Kekuatan Chassis Go-Kart Akibat Beban Belok
}

\author{
Yulian D. S. Wibisana dan Julendra B. Ariatedja \\ Departemen Teknik Mesin, Fakultas Teknologi Industri \\ Institut Teknologi Sepuluh Nopember (ITS) 60111 Indonesia \\ e-mail: ariatedja@me.its.ac.id
}

\begin{abstract}
Abstrak-Dalam berkompetisi, go-kart dituntut mampu lincah saat berbelok. Namun, differential gear dan sistem suspensi ditiadakan dalam komponen standar perlombaan. Padahal, komponen ini berpengaruh pada performa belok kendaraan. Kedua fungsi komponen tersebut dikompensasi melalui chassis go-kart yang didesain tidak hanya kuat menahan beban, namun juga harus cukup fleksibel (khususnya terkait kekakuan torsional). Go-kart memanfaatkan efek jacking dari chassis dalam meningkatkan kemampuan berbeloknya. Oleh karena itu, penelitian kali ini bertujuan melihat hubungan kekakuan torsional dari chassis go-kart dengan efek jacking yang mampu dihasilkan dalam kondisi pembebanan aktual. Analisis chassis tersebut akan dilakukan dengan menggunakan metode elemen hingga. Di mana tiga model chassis go-kart akan diberikan pembebanan torsional dan juga pembebanan belok. Pada pembebanan torsional, chassis akan diberikan beban torsional sehingga akan menghasilkan besar torsional rigidity yang menggambarkan nilai kekakuan chassis tersebut. Kemudian, simulasi pembebanan belok akan digunakan untuk mengetahui jacking dan karakter kekuatan dari chassis tersebut. Selain itu, beban pengereman yang terjadi saat berbelok juga akan dianalisa efeknya pada efek jacking dan kekuatan chassis. Setelah simulasi dan analisis telah dilakukan. Maka, hasil memperlihatkan bahwa chassis tony kart merupakan chassis yang paling fleksibel daripada chassis lainnya dengan torsional rigidity 188,6 Nm/deg, dan chassis birell merupakan chassis yang paling kaku dengan torsional rigidity 277,7 Nm/deg. Dan chassis arrow dengan torsional rigidity 243,75 Nm/deg. Setelah diteliti diketahui bahwa semakin fleksibel chassis akan mempermudah terjadinya efek jacking pada kendaraan. Kemudian, kekuatan chassis yang paling baik dimiliki oleh go-kart dengan tipe chassis arrow. Sementara itu, beban pengereman dengan jarak pengereman 3 meter dan perlambatan $20,8 \mathrm{~m} / \mathrm{s}^{2}$ saat berbelok didapatkan membuat go-kart lebih mudah mengalami jacking (rata-rata kenaikan jacking $67 \%$ ). Namun, beban ini dapat membuat tegangan maksimal yang diterima chassis bertambah (rata-rata kenaikan tegangan maksimal $21 \%$ ).
\end{abstract}

Kata Kunci-Chassis, Deformasi, Go-kart, Jacking, Metode Elemen Hingga, Tegangan Von Mises.

\section{PENDAHULUAN}

G $O-K A R T$ pertama kali diperkenalkan di Indonesia pada tahun 1967 oleh Hengky Iriawan. Gagasan pembuatan mesin go-kart sendiri berasal dari beberapa mahasiswa ITB (Institut Teknologi Bandung) Jurusan Mesin saat itu[1]. Gokart biasanya tidak dilengkapi dengan differential gear dan sistem suspensi untuk memenuhi standar perlombaan. Differential gear berfungsi untuk mengatur agar roda belakang bagian dalam dapat berputar dengan kecepatan sudut yang sama dengan roda belakang bagian luar ketika berbelok. Tidak adanya differential ini dapat mengurangi performa go-kart untuk berbelok dengan lincah dalam perlombaan. Maka, go-kart didesain agar roda belakang bagian dalamnya dapat terangkat ketika berbelok untuk mengatasi keterbatasan ini. Fenomena ini biasanya disebut oleh beberapa komunitas go-kart sebagai efek jacking.

Chassis kendaraan adalah komponen kendaraan yang fungsi utamanya adalah sebagai rangka penguat konstruksi bodi kendaraan agar mampu menahan beban kendaraan dan beban impak saat terjadi tabrakan sehingga melindungi penumpang[2]. Chassis go-kart selain didesain kuat untuk menahan beban kendaraan. Chassis juga harus didesain cukup fleksibel terhadap kekakuan torsional sehingga memungkinkan terjadinya jacking. Selain itu, fleksibilitas ini juga dimaksudkan sebagai pengganti sistem suspensi yang tidak ditemui pada go-kart. Sehingga, analisis terkait nilai kekakuan torsional, efek jacking, dan kekuatan chassis gokart merupakan hal penting yang perlu diperhatikan saat mendesain suatu go-kart.

Mirone pernah meneliti tentang sifat fleksibilitas chassis go-kart dengan memberikan pembebanan torsional menggunakan metode eksperimental. Mirone menjelaskan bahwa fleksibilitas chassis go-kart memiliki peran penting sebagai pengganti sistem suspensi yang tidak dimiliki gokart. Pada penelitiannya, chassis go-kart diberikan beban torsi dengan memberi bagian belakang kendaraan tumpuan fix. Di mana penelitiannya menunjukkan besar deformasi vertikal terhadap beban torsi yang diberikan dari go-kart yang diteliti dan kaitannya dengan performa dinamis kendaraan[3].

Liang, dkk meneliti pula tentang sifat fleksibilitas chassis go-kart dengan memberikan pembebanan torsional. Pada penelitiannya, Liang, dkk menggunakan metode simulasi pada software finite element method LS-DYNA 3D. Liang, dkk menjelaskan dalam penelitiannya bahwa fleksibilitas chassis go-kart penting sebagai pengganti sistem suspensi dan membantu go-kart saat melakukan cornering. Chassis go-kart yang diteliti Liang,dkk dimodelkan dan diberi pembebanan dengan menumpu bagian belakang chassis dengan tumpuan fix. Sementara bagian depan chassis diberikan beban torsi. Hasil akhir dari penelitian ini berupa angle of twist dan torsional rigidity dari beberapa model chassis yang nantinya dibandingkan satu sama lain[4]. Dari penjelasan tersebut dapat dilihat bahwa penelitian tentang chassis go-kart telah beberapa kali dilakukan.

Oleh karena itu, penelitian lebih lanjut tentang kekakuan chassis go-kart dan kaitannya terhadap efek jacking serta kekuatan dari chassis terutama saat berbelok masih perlu dilakukan Penelitian kali ini akan dilakukan dengan memodelkan tiga chassis go-kart dari kelompok yang berbeda. Kemudian, chassis go-kart akan dianalisa menggunakan bantuan software berbasis metode elemen hingga (finite element method) dengan diberikan pembebanan kuasi statis yang mewakili kondisi nyata beban pada kendaraan. Dalam penelitian kali ini, chassis go-kart akan dianalisa menggunakan kondisi beban keadaan berbelok dan juga beban torsional. Sehingga nantinya dapat diketahui besar 
kekakuan torsional dan kekuatan chassis serta pengaruhnya terhadap efek jacking dengan menggunakan metode elemen hingga. Selain itu, penelitian ini akan melihat juga pengaruh beban pengereman yang diterima chassis saat berbelok terhadap efek jacking dan kekuatan chassis.

\section{METODE PENELITIAN}

\section{A. Model Chassis yang Diteliti}

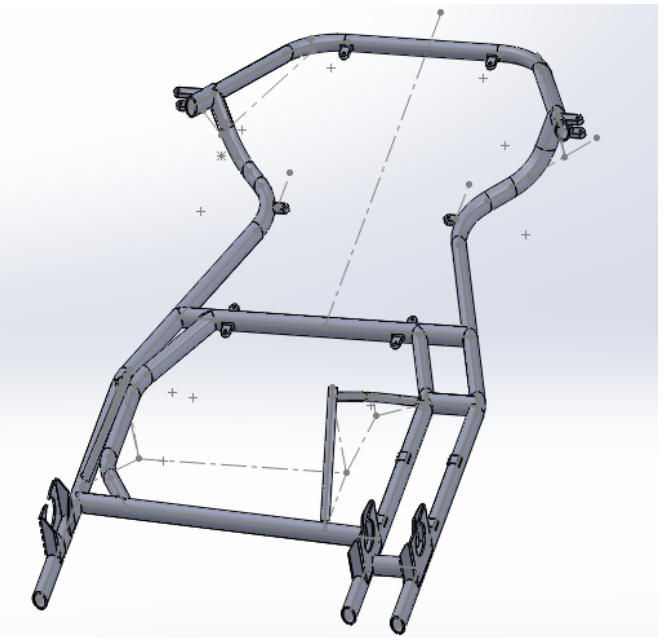

Gambar 1. Model Tiga Dimensi dari Chassis Go-kart Tipe Birell

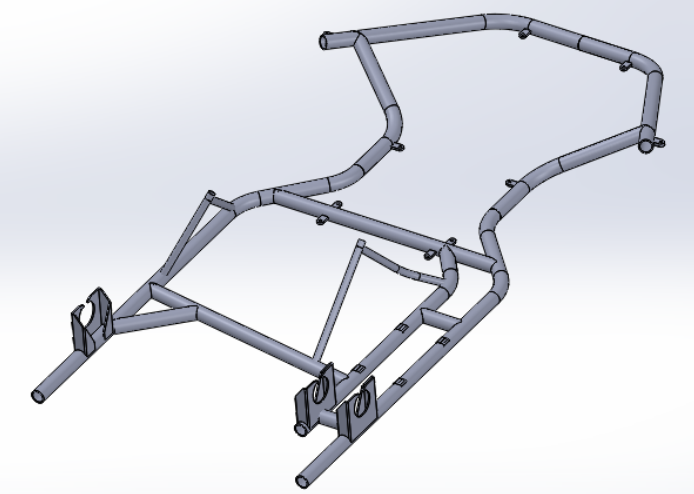

Gambar 2. Model Tiga Dimensi dari Chassis Go-kart Tipe Tony Kart

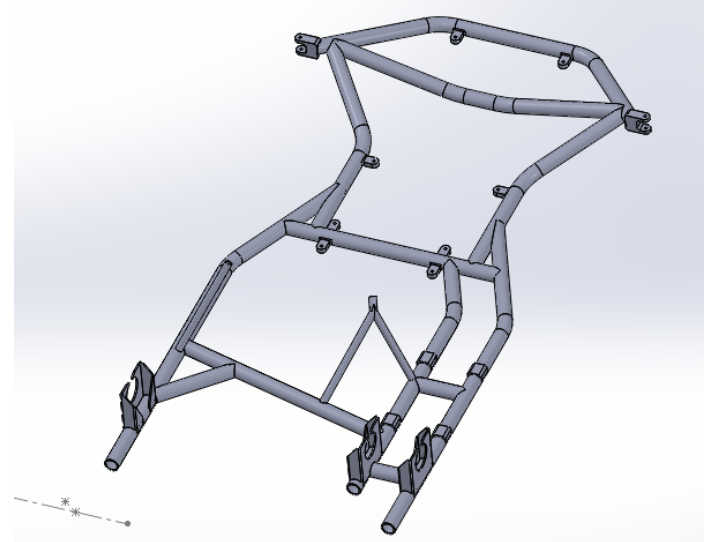

Gambar 3. Model Tiga Dimensi dari Chassis Go-kart Tipe Arrow

Pada penelitian kali ini akan diteliti tiga model chassis yang terlihat pada gambar 1, 2, dan 3. Di mana penelitian akan melihat torsional rigidity, efek jacking, dan karakter kekuatan dari chassis tersebut.

\section{B. Material Chassis}

Tabel 1.

Mechanical Property Material Aisi 4130 Chromolly[5]

\begin{tabular}{lc}
\hline \hline \multicolumn{1}{c}{ Properties } & Metric \\
\hline Density & $7,85 \mathrm{~g} / \mathrm{cm}^{3}$ \\
Melting Point & $1432^{\circ} \mathrm{C}$ \\
Tensile Strength ,Ultimate & $560 \mathrm{MPa}$ \\
Tensile Strength, Yield & $460 \mathrm{MPa}$ \\
Modulus Elasticity & $190-210 \mathrm{GPa}$ \\
Poissons Ratio & $0,27-0,30$ \\
Bulk Modulus & $140 \mathrm{GPa}$ \\
Shear Modulus & $80 \mathrm{GPa}$ \\
Hardness, Brinell & 217 \\
Elongation at Break (in $50 \mathrm{~mm}$ ) & $21,5 \%$ \\
Reduction of area & $59,6 \%$ \\
\hline
\end{tabular}

\section{Simulasi Beban Belok}

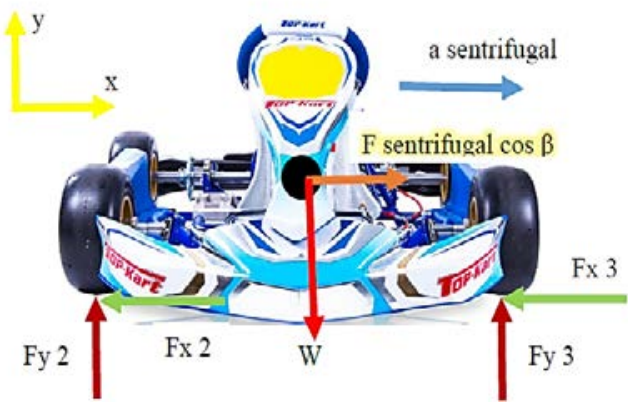

Gambar 4. Free Body Diagram Go-kart saat Berbelok ke Kiri pada Tampak Depan

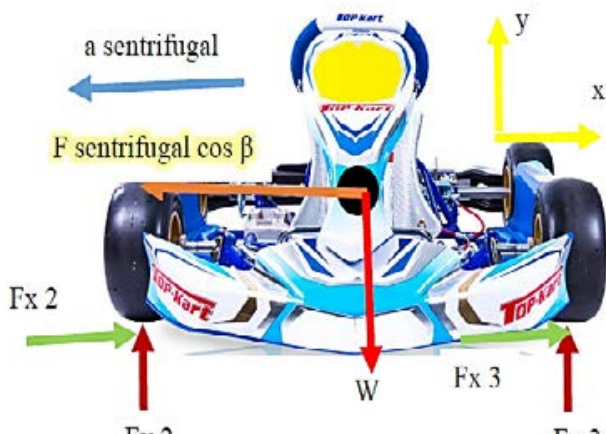

Fy 2

Fy 3

Gambar 5. Free Body Diagram Go-kart saat Berbelok ke Kanan pada Tampak Depan

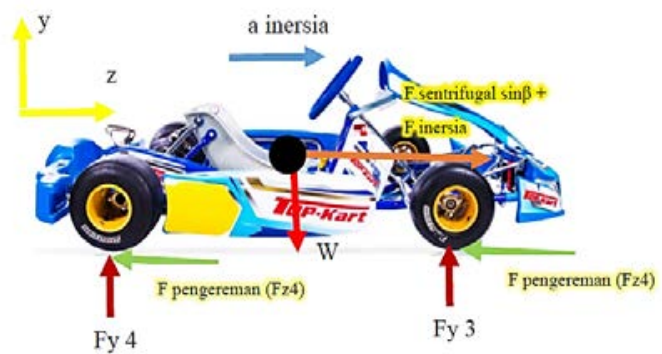

Gambar 6. Free Body Diagram Go-kart saat Berbelok pada Tampak Samping

Gambar 4 menunjukkan free body diagram dari go-kart saat berbelok ke arah kiri. Saat go-kart berbelok, go-kart akan mengalami gaya sentrifugal ke arah lateral luar arah belok kendaraan. Kemudian go-kart akan mengalami pula gaya berat kendaraan yang memiliki arah vertikal ke bawah. Pada roda go-kart akan terdapat gaya reaksi yang memiliki arah lateral maupun vertikal. Pada saat go-kart berbelok ke kanan, 
rincian gaya yang bekerja pada chassis akan sama besar namun memiliki arah yang berbeda seperti yang ditunjukkan pada gambar 5 .

Besar gaya sentrifugal pada penelitian kali ini akan divariasikan besarnya dengan menvariasikan kecepatan kendaraan pada $40 \mathrm{~km} / \mathrm{h}, 45 \mathrm{~km} / \mathrm{h}$, dan $50 \mathrm{~km} / \mathrm{h}$ dengan radius belok tetap sebesar 4,6 m. Variasi ini dilakukan untuk melihat pengaruh besar gaya sentrifugal terhadap kenaikan roda belakang (jacking) dan juga kekuatan chassis. Penelitian kali ini akan mensimulasi ketiga chassis dengan material yang sama yaitu AISI 4130 Chromolly yang memiliki mechanical property yang ditunjukkan pada gambar tabel 1.

Gambar 6 menunjukkan free body diagram dari go-kart saat berbelok pada tampak samping. Saat go-kart berbelok, go-kart juga akan menerima gaya sentrifugal ke arah longitudinal yang disebabkan adanya sudut side slip kendaraan. Pada saat go-kart tidak melakukan pengereman ketika berbelok maka kendaraan hanya akan menerima beban sentrifugal arah longitudinal ini saja. Namun, saat go-kart berbelok dengan melakukan pengereman, go-kart akan menerima gaya inersia tambahan akibat beban pengereman tersebut yang memiliki arah longitudinal.

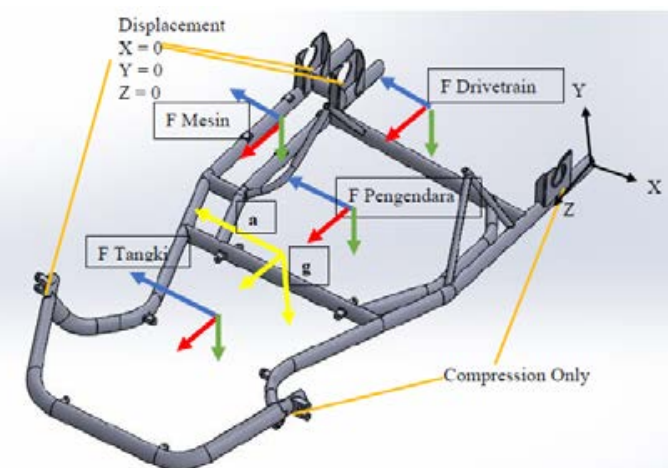

Gambar 7. Boundary Condition Simulasi Go-kart Berbelok ke Kiri

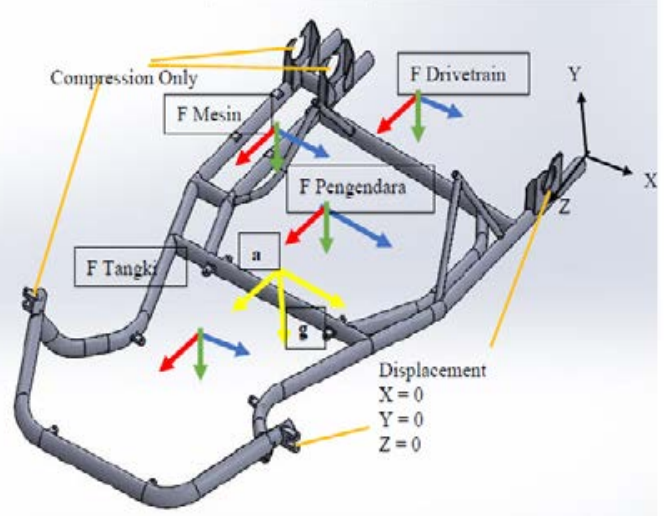

Gambar 8. Boundary Condition Simulasi Go-kart Berbelok ke Kanan

Gambar 7 menunjukkan bahwa pada simulasi pembebanan belok ke kiri, chassis akan diberikan support berupa displacement $\mathrm{x}=0, \mathrm{y}=0$, dan $\mathrm{z}=0$ pada tempat peletakan roda bagian luar. Kemudian chassis juga akan diberikan support compression only pada peletakan roda bagian dalam yang diharapkan dapat terangkat saat go-kart sedang berbelok. Saat go-kart berbelok ke kanan, rincian peletakan boundary condition pada saat simulasi akan sama peletakannya hanya saja memiliki arah sebaliknya dari pada saat berbelok ke arah kiri seperti ditunjukkan pada gambar 8 .

Simulasi beban belok ini akan menggunakan koordinat kartesian dengan arah dan peletakan titik origin dapat dilihat pada gambar 7 dan 8 . Kemudian, hasil simulasi yang akan dicari simulasi ini adalah von misses stress, deformation arah y, dan safety factor. Hasil deformation arah y ini akan dilihat untuk daerah roda belakang bagian dalam. Karena bagian tersebut akan memperlihatkan terangkat atau tidaknya roda kendaraan (efek jacking). Sementara hasil von misses stress dan safety factor akan digunakan untuk melihat karakter kekuatan dari tiga jenis chassis yang diteliti.

\section{Simulasi Beban Torsional}

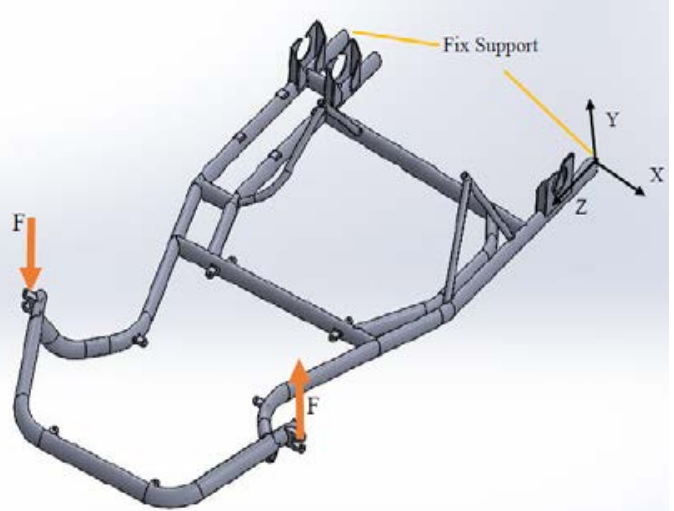

Gambar 9. Boundary Condition Simulasi Go-kart pada Pembebanan Torsional

Gambar 9 menunjukkan bahwa pada simulasi pembebanan torsional akan diberikan fix support pada bagian belakang chassis. Kemudian chassis akan diberi gaya kopel pada peletakan roda depan. Besar gaya kopel ini besarnya akan didapat dari persentase berat kendaraan. Di mana akan divariasikan besar $\mathrm{F}$ pada 0,$2 ; 0,4 ; 0,6 ; 0,8$; dan 1,0 dari berat kendaraan. Simulasi kali ini akan menggunakan koordinat kartesian seperti pada gambar 5 . Kemudian, hasil yang akan dicari dari simulasi adalah deformasi Y. Dari hasil tersebut bisa didapat besar sudut puntir dan torsi puntir yang nantinya dapat dihitung untuk mencari nilai torsional rigidity chassis.

\section{HASIL DAN PEMBAHASAN}

\section{Perbandingan Besar Torsional Rigidity}

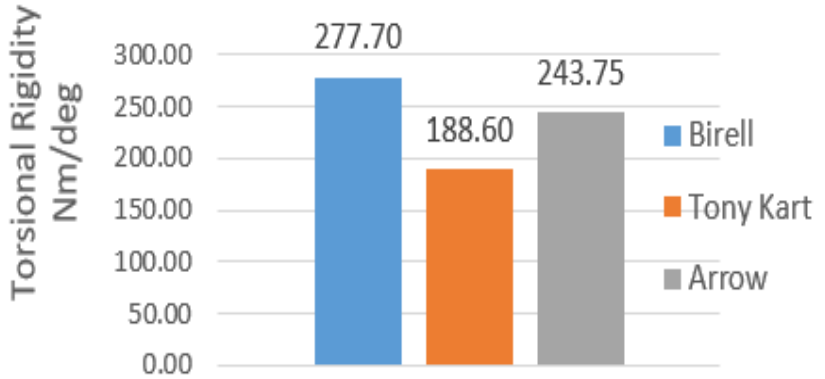

Gambar 10. Hasil Simulasi berupa Torsional Rigidity dari Chassis yang Diteliti

Hasil Jacking Belok ke Kiri

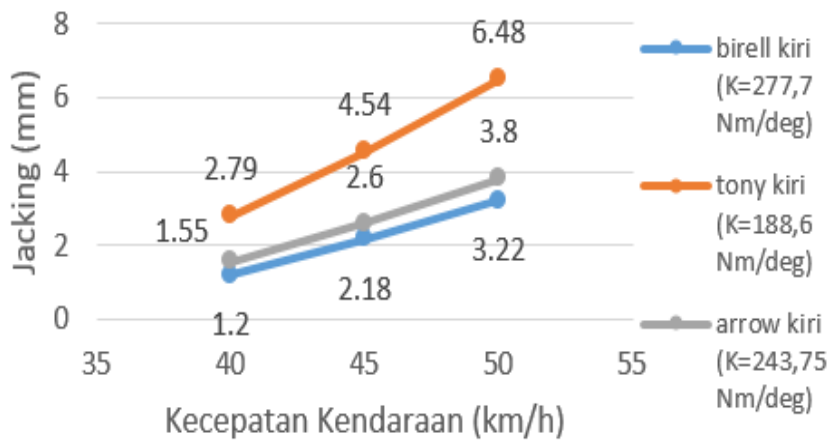


Gambar 11. Hasil Efek Jacking saat Go-kart Berbelok ke Kiri Tanpa Mengalami Beban Pengereman

\section{Hasil Jacking Belok ke Kanan}

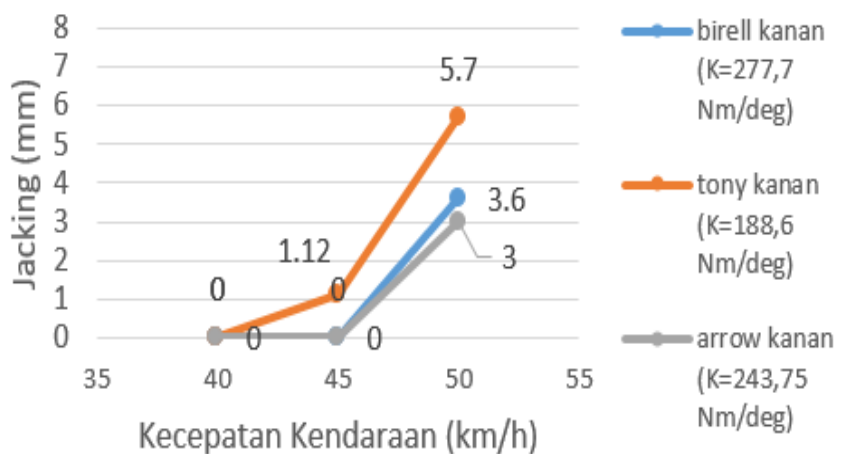

Gambar 12. Hasil Efek Jacking saat Go-kart Berbelok ke Kanan Tanpa Mengalami Beban Pengereman

Hasil Tegangan Maksimal Belok ke Kiri

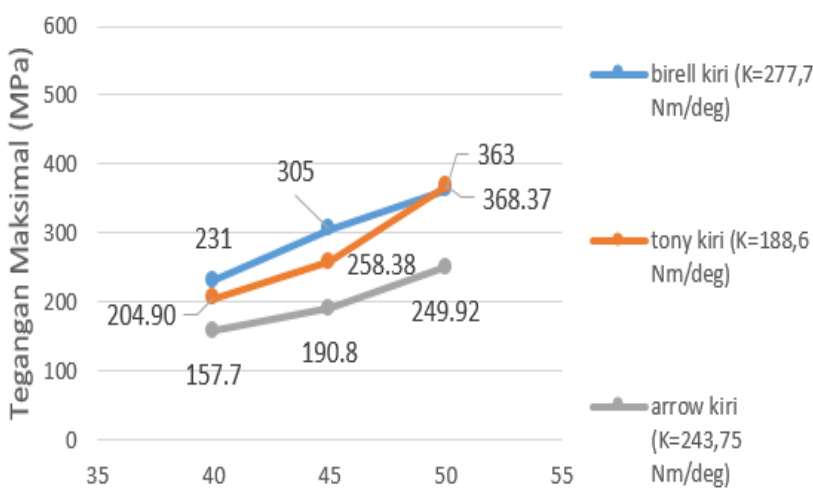

Kecepatan Kendaraan $(\mathrm{km} / \mathrm{h})$

Gambar 13. Hasil Tegangan Maksimal saat Go-kart Berbelok ke Kiri Tanpa Mengalami Beban Pengereman

Hasil Tegangan Maksimal Belok ke Kanan

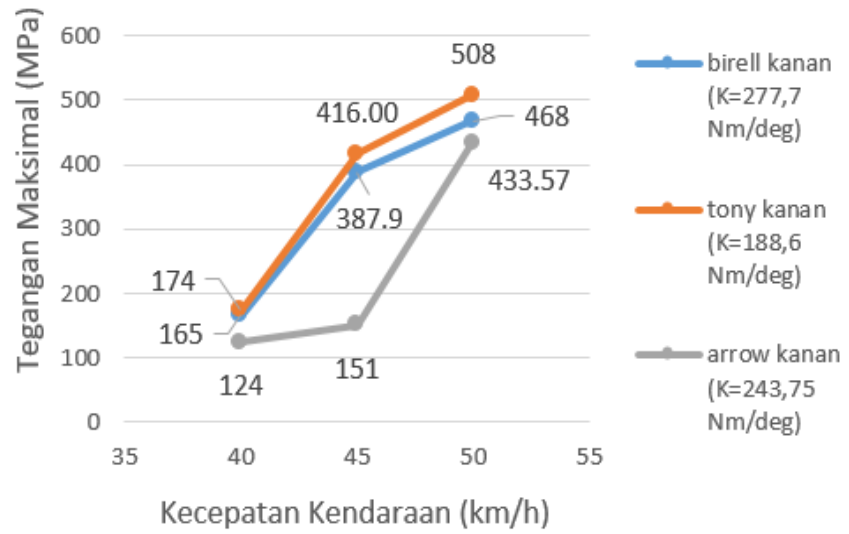

Gambar 14. Hasil Tegangan Maksimal saat Go-kart Berbelok ke Kanan Tanpa Mengalami Beban Pengereman
Hasil Jacking Belok ke Kiri \& Efek Pengereman

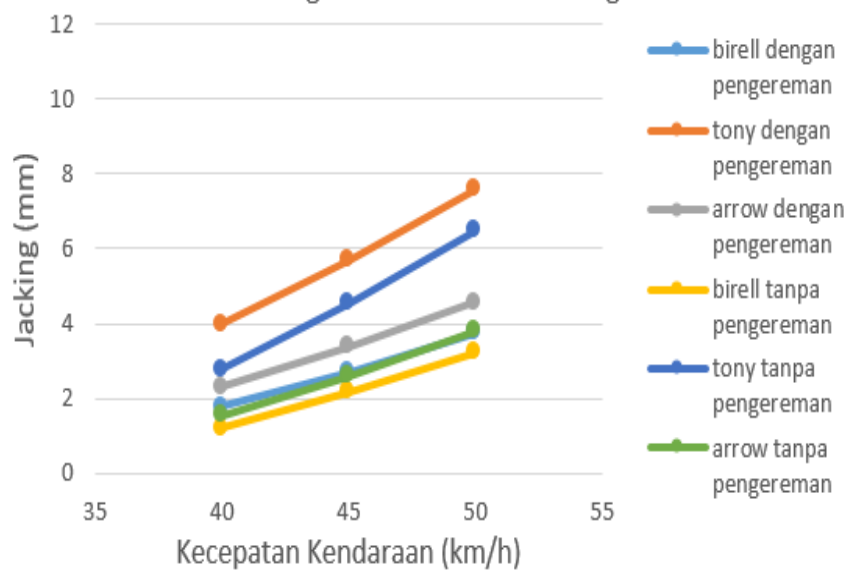

Gambar 15. Perbandingan Hasil Jacking Chassis pada Pembebanan Berbelok Kiri Tanpa Beban Pengereman maupun dengan Beban Pengereman Hasil Jacking Belok ke Kanan \& Efek Pengereman

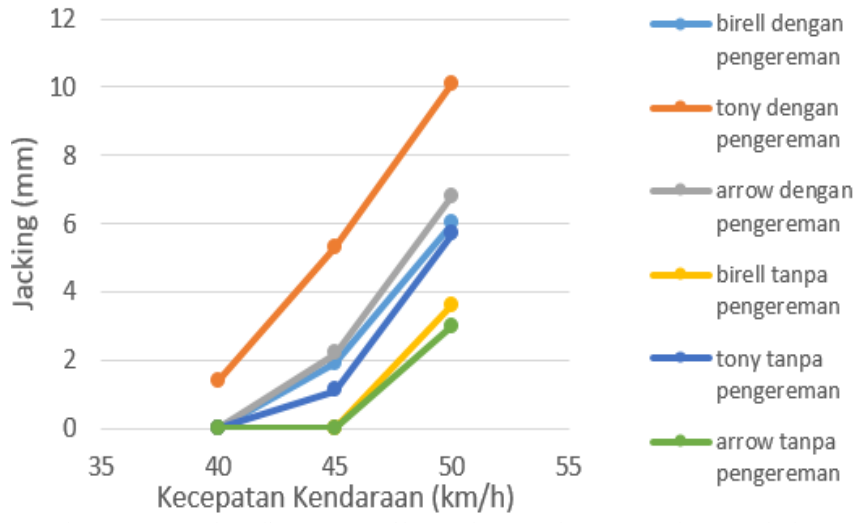

Gambar 16. Perbandingan Hasil Jacking Chassis pada Pembebanan Berbelok Kanan Tanpa Beban Pengereman maupun dengan Beban Pengereman

Hasil Tegangan Maksimal Belok ke Kiri \& Efek Pengereman

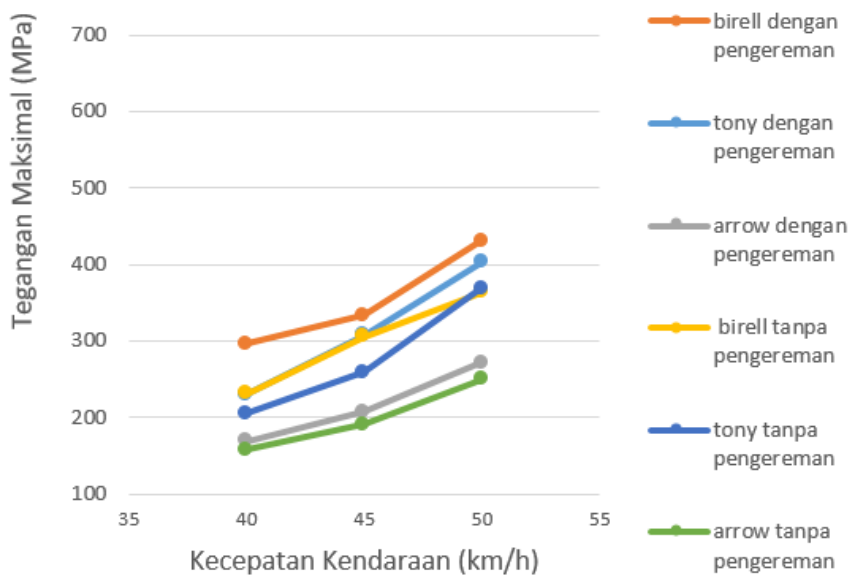

Gambar 17. Perbandingan Hasil Tegangan Maksimal Chassis pada Pembebanan Berbelok Kiri Tanpa Beban Pengereman maupun dengan Beban Pengereman 


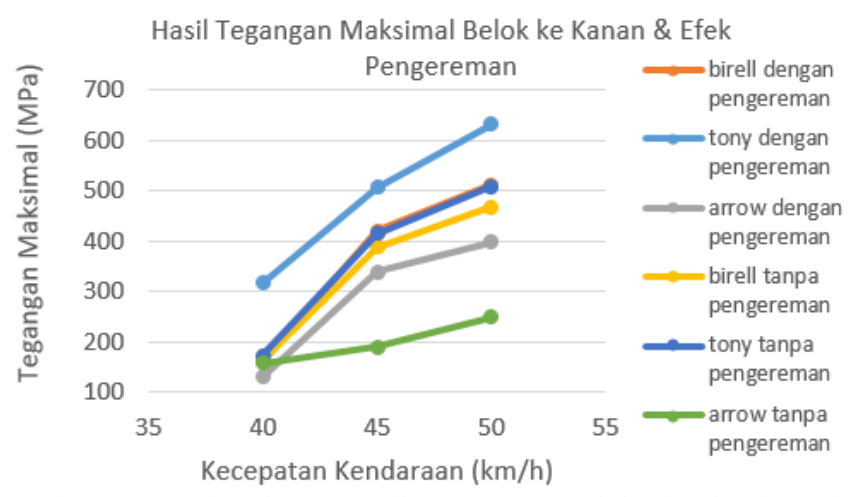

Gambar 18. Perbandingan Hasil Tegangan Maksimal Chassis pada Pembebanan Berbelok Kanan Tanpa Beban Pengereman maupun dengan Beban Pengereman

Gambar 10 menunjukkan bahwa chassis birell berpenampang oval merupakan chassis paling kaku dengan torsional rigidity 277,7 Nm/deg. Chassis Tony Kart berpenampang lingkaran merupakan chassis paling fleksibel dengan torsional rigidity 188,6 Nm/deg. Chassis Arrow berpenampang lingkaran berada di tengah kekakuannya dengan torsional rigidity 243,75 Nm/deg. Hasil simulasi memperlihatkan bahwa chassis yang pernampang oval memiliki kekakuan yang lebih tinggi dari chassis berpenampang lingkaran. Hal ini menunjukan bahwa bentuk dan ukuran penampang chassis juga memiliki pengaruh pada besar kekakuan chassis.

Gambar 11 dan 12 menunjukkan bahwa go-kart dengan chassis tony kart yang paling fleksibel cenderung lebih mudah untuk mengalami efek jacking daripada chassis lainnya. Sementara chassis birell yang paling kaku cenderung lebih sulit untuk mengalami efek jacking dibanding chassis lainnya. Sementara chassis arrow berada diantara kedua chassis tersebut pada besar efek jacking yang terjadi. Hasil tersebut memperlihatkan bahwa kekakuan chassis berpengaruh pada efek jacking. Gambar 11 dan 12 juga memperlihatkan bahwa go-kart lebih mudah untuk mengalami jacking saat berbelok ke kiri daripada saat berebelok ke kanan.

Gambar 13 dan 14 menunjukkan bahwa chassis arrow memiliki tegangan maksimal yang paling kecil daripada chassis lainnya baik saat berbelok ke kanan maupun ke kiri. Sementara chassis birell cenderung memiliki tegangan lebih kecil daripada chassis tony kart saat kendaraan berbelok ke kanan. Sedangkan chassis tony kart cenderung memiliki tegangan lebih kecil daripada chassis birell saat kendaraan berbelok kekiri. Chassis go-kart yang diteliti juga cenderung mengalami tegangan maksimal yang lebih besar saat go-kart berbelok ke kanan daripada saat berbelok ke kiri.

Gambar 15 dan 16 menunjukkan bahwa beban pengereman pada jarak 3 meter dan besar 20,8 m/s² membuat kendaraan mengalami peningkatan pada besar jacking dengan kenaikan rata-rata pada chassis birell 38,9\%, chassis tony kart $106 \%$, dan chassis arrow 39,8 \%. Sehingga rata-rata keseluruhan kenaikan jacking akibat penambahan beban pengereman ini sebesar $67 \%$.

Gambar 17 dan 18 menunjukkan bahwa beban pengereman pada jarak 3 meter dan besar perlambatan 20,8 m/s membuat kendaraan mengalami peningkatan tegangan maksimal dengan kenaikan rata-rata pada chassis birell $12 \%$, chassis tony kart 28,2 \%, dan chassis arrow $31 \%$. Sehingga rata-rata keseluruhan kenaikan tegangan maksimal akibat penambahan beban pengereman ini sebesar $21 \%$.

\section{KESIMPULAN}

1. Chassis tipe birell merupakan chassis paling kaku. Disusul chassis tipe arrow berada di tengah. Lalu, chassis tipe tony kart berpenampang lingkaran menjadi chassis paling fleksibel.

2. Chassis tipe arrow menjadi chassis yang paling kuat. Kemudian dibawahnya, chassis tipe tony kart lebih kuat daripada tipe birell saat go-kart berbelok ke arah kiri. Sementara ketika go-kart berbelok ke arah kanan, chassis tipe birell memiliki kekuatan yang lebih baik daripada chassis tipe tony kart.

3. Secara keseluruhan dapat disimpulkan bahwa semakin fleksibel chassis maka semakin mudah chassis tersebut untuk mengalami efek jacking.

4. Beban pengereman pada jarak pengereman 3 meter dan besar perlambatan $20,8 \mathrm{~m} / \mathrm{s}^{2}$ dapat membuat go-kart lebih mudah untuk mengalami efek jacking (rata-rata kenaikan besar jacking 67 \%). Namun, beban ini juga dapat meningkatkan tegangan maksimal yang diterima oleh chassis (rata-rata kenaikan tegangan maksimal $21 \%)$.

5.

\section{DAFTAR PUSTAKA}

[1] Ikatan Motor Indonesia (IMI), “Karting.” [Online]. Available: http://www.imi.co.id/olahraga/category/karting. [Accessed: 07-Jan2018].

[2] B. S.I. Nyoman., Sampurno, Teknologi Otomotif Edisi Kedua. Guna Widya, 2010.

[3] G. Mirone, "Multi-body elastic simulation of a go-kart: Correlation between frame stiffness and dynamic performance,” Int. J. Automot Technol., vol. 11, no. 4, pp. 461-469, Aug. 2010.

[4] C.-C. Liang, C.-H. Yu, and C.-C. Wu, "A study on torsional stiffness of the competition go-kart frame," Comput. Aided Optim. Des. Eng. X, vol. 91, pp. 189-198, Apr. 2007.

[5] AZoM, “AISI 4130 Alloy Steel (UNS G41300),” AZO Materials, $2012 . \quad$ [Online]. Available: https://www.azom.com/article.aspx?ArticleID=6742. [Accessed: 07Jan-2019]. 